\title{
Hip Hype: FAl Syndrome, Amara's Law, and the Hype Cycle
}

\author{
Ara Kassarjian, MD, FRCPC ${ }^{1}$ \\ ${ }^{1}$ Musculoskeletal Radiology, Elite Sports Imaging, SL Madrid, Spain \\ Semin Musculoskelet Radiol 2019;23:252-256.
}

\begin{abstract}
Address for correspondence Ara Kassarjian, MD, FRCPC, Musculoskeletal Radiology, Elite Sports Imaging, SL Madrid, Spain (e-mail: kassarjian@me.com).
\end{abstract}
Abstract
Keywords
- hip
- impingement
- MRI
- femoroacetabular
- joint

Femoroacetabular impingement (FAI) has taken us on a roller-coaster ride of innovation, heightened expectations, disillusionment, and confusing diagnostic and treatment pathways. This article reviews and analyzes the phases of FAl diagnosis and treatment over the past 15 years and discusses its parallels to Amara's law and Gartner's hype cycle.
Since the appearance of femoroacetabular impingement (FAI) on the world stage in 2003 following Ganz et al's publication on FAI as a cause for osteoarthritis (OA) of the hip, ${ }^{1}$ the medical and athletic community, and, to a lesser extent, people with hip pain in the general population, have been taken on a rollercoaster ride: confusing definitions and promises of pain relief, prevention of the onset of OA, delaying of progression of OA, overall uncertainty, and mixed results.

\section{How Did We Get Here?}

Much of this confusion began with the advent of a surgical technique that allowed safe dislocation of the hip. ${ }^{2}$ Ganz and colleagues meticulously studied hip joint anatomy and, specifically, the vascular anatomy of the femoral head. ${ }^{3}$ After ascertaining that the medial femoral circumflex artery was the main contributor to femoral head perfusion, and that the ligamentum teres and its associated vestigial artery had little, if any, role in femoral head perfusion in adults, they developed a technique for safe surgical dislocation of the femoral head with minimal, if any, risk of femoral head osteonecrosis. This surgical technical development was a key factor in the subsequent developments of what we now refer to as femoroacetabular impingement syndrome (FAI syndrome, or FAIS).

With the ability to dislocate the hip safely, Ganz et al were able to better visualize the entirety of the femoral head, the femoral head-neck junction, and the acetabular fossa. This extended visualization allowed them to get a better appreciation of the three-dimensional morphology of the proximal femur, the acetabulum, and the various associated lesions. With this improved in vivo visualization, the mechanical concept of FAI and its association with hip OA was born. ${ }^{1}$

\section{Medicine and Technology}

The promises of new technologies (and techniques) seem an appropriate simile for what we often see in medicine, especially as medicine becomes more and more technological every year. Consider the remarkable advances in only the last few decades regarding imaging and surgical tools and techniques. The sheer volume is staggering in general, and in hip imaging and treatment in particular. Without going into details, in the United States, hip arthroscopies increased $117 \%$ from 2007 to 2014, and extended billing codes increased $475 \%$ in that same period. ${ }^{4}$

In many ways, the technical development of safe surgical dislocation of the hip followed Roy Amara's law: "We tend to overestimate the effect of a technology in the short run and underestimate the effect in the long run"(2006). ${ }^{5}$

\section{Amara's Law}

The technological development of safe dislocation of the hip not only triggered the theory of FAI as a cause of OA, it also provided a way to treat what was thought to be the cause of the symptoms: the so-called bump at the femoral head-neck junction, what we now refer to as cam morphology. To a lesser degree, at least initially, the surgical dislocation also
Issue Theme Hip and Advanced Musculoskeletal Imaging; Guest Editors, Vasco V. Mascarenhas, MD, MBA and Alberto Vieira, MD
Copyright (c) 2019 by Thieme Medical Publishers, Inc., 333 Seventh Avenue, New York, NY 10001, USA. Tel: +1(212) 584-4662. ISSN 1089-7860. 
allowed surgeons to address the results of the abnormal contact between the proximal femur and the acetabulum: labral tears and cartilage lesions.

As per Amara's law, the effect of this technology/technique of safe dislocation of the hip was initially overestimated. There were promises of prevention of primary OA to the point that some centers were performing prophylactic osteochondroplasties to correct the cam lesion (morphology) in asymptomatic patients, believing it would prevent the development of labral lesions, cartilage lesions, symptoms, and $\mathrm{OA}$. The need for treatment of all hips with a cam or pincer morphology was, as we now appreciate, overestimated. ${ }^{6}$ The ability to decrease pain and prevent $\mathrm{OA}$ in all patients may have been overestimated as well.

On the flip side, the long-term effects of this technology/ technique were underestimated. As open FAI surgery became popular, some pioneers began trying to address the osseous and soft tissue lesions via arthroscopy. Before then, hip arthroscopy was quite rare, only performed by a few arthroscopists, and generally at low volumes for very limited indications. The recognition of FAI as a cause of hip pain lead to an unexpected and, as per Amara's law, underestimated effect: a rapid and sustained increase in the volume of hip arthroscopies. ${ }^{4,7}$ There was an associated improvement in arthroscopic techniques and devices including specially designed scopes, shavers, and burrs. What was previously a rare procedure very quickly became a very common procedure that within a short period of time was being performed by thousands of arthroscopists worldwide (-Fig. 1). The underestimated long-term effect of Ganz's safe dislocation of the hip was the resulting boom in hip arthroscopies worldwide and not only for FAI surgery.

This boom in hip surgery, specifically hip arthroscopy, resulted in exponential and essentially parallel rises in research activity and the number of articles published regarding hip arthroscopy and hip impingement. The two went hand in hand (-Fig. 2), with a clear inflection point shortly after 2003 when Ganz's sentinel article was published.

\section{The Hype Cycle}

In addition to the trends in surgical techniques and associated developments, the overall concept of FAI including its presentation, diagnosis, and treatment was a classic example of hype. We often see this type of hype in the world of technology and medicine. In fact, Gartner refers to the hype cycle as a representation of the maturation and adoption of technologies and applications (- Fig. 3) in these steps: ${ }^{9}(1)$ technology trigger; (2) peak of inflated expectations; (3) trough of disillusionment; (4) slope of enlightenment; and (5) plateau of productivity.

Initially, there is a big media blitz about an amazing new discovery (technology trigger). Headlines and sensationalist stories follow about the promises of the new technology and how it will change the way we live (peak of inflated expectations). As experience accumulates, it becomes clear that the new technology, although it may be quite good, is not as far reaching as initially marketed or anticipated. This leads to a sense of disappointment and perhaps even deception (trough of disillusionment). However, as further experience accrues, there is a period during which the true and optimal use/applications of the new technology become apparent (slope of enlightenment). In the final phase, the advantages and shortcomings of the new technology are understood well enough to be able to apply it in a manner that is efficient, productive, and optimized (plateau of productivity).

\section{Hip Hype}

As with the technological hype cycle, FAIS followed, and continues to follow, a similar cycle (-Fig. 4).

1. Safe surgical dislocation of hip (Innovation trigger): As previously mentioned, the ability to dislocate the hip safely allowed global visualization of the hip, specifically the variations of femoral head-neck morphology and the location and types of cartilage and labral damage. This better visualization led to the better understanding of the three-dimensional interaction between the femur and the

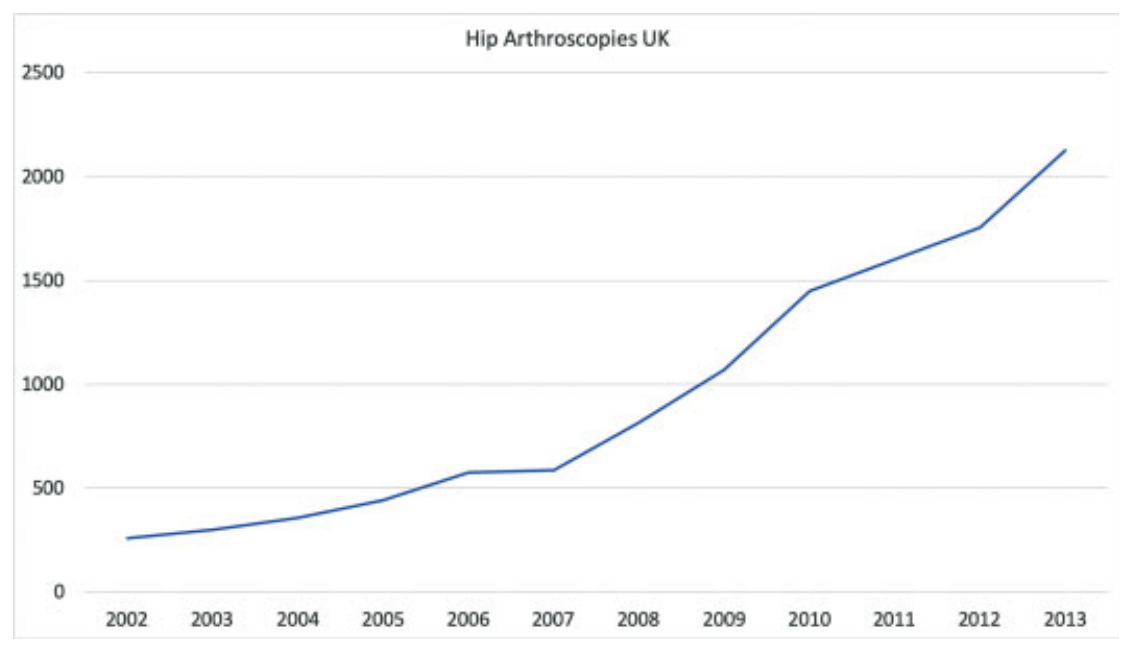

Fig. 1 Trends in hip arthroscopy in the United Kingdom (UK), 2002-2013. There was more than a fivefold increase in the number of hip arthroscopies in 11 years. $^{7}$ 


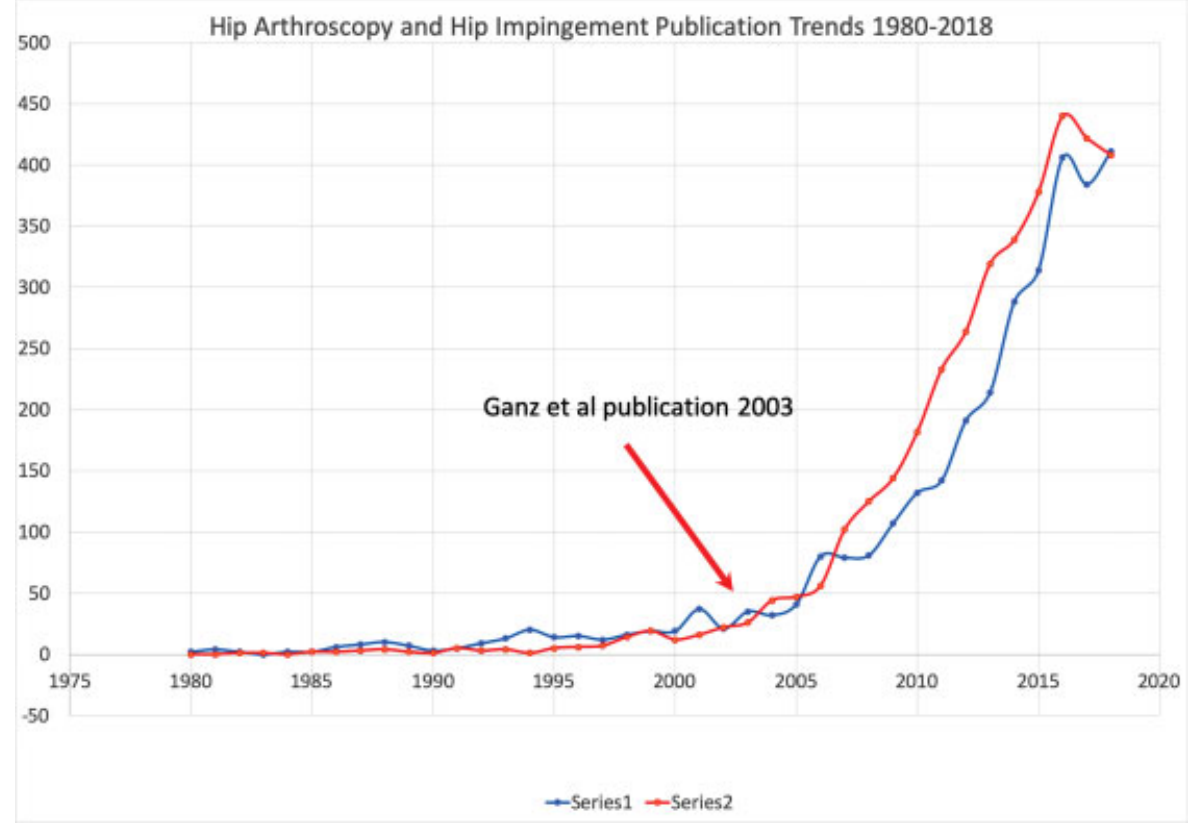

Fig. 2 Trends in publications for hip arthroscopy and hip impingement, 1980-November 2018. There was a clear and dramatic increase in the number of publications on hip arthroscopy (red) and hip impingement (blue) after the publication of the sentinel article by Ganz et al in 2003 proposing femoroacetabular impingement as a cause of hip osteoarthritis. ${ }^{8}$

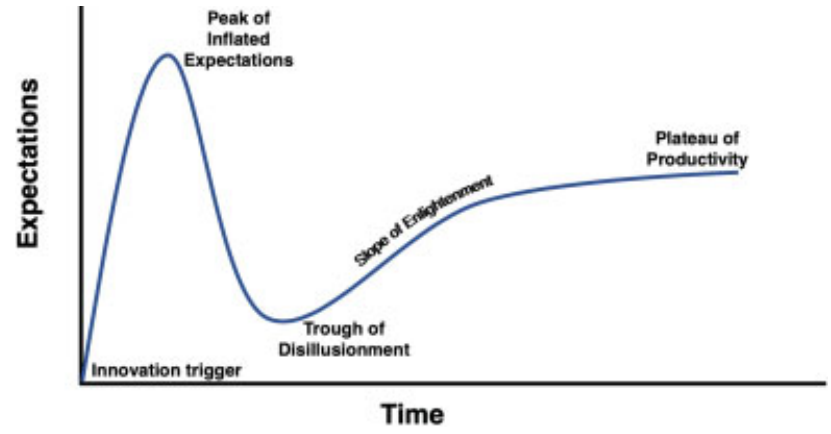

Fig. 3 The hype cycle. The phases of the hype cycle as they relate to new technologies (adapted from reference 9).

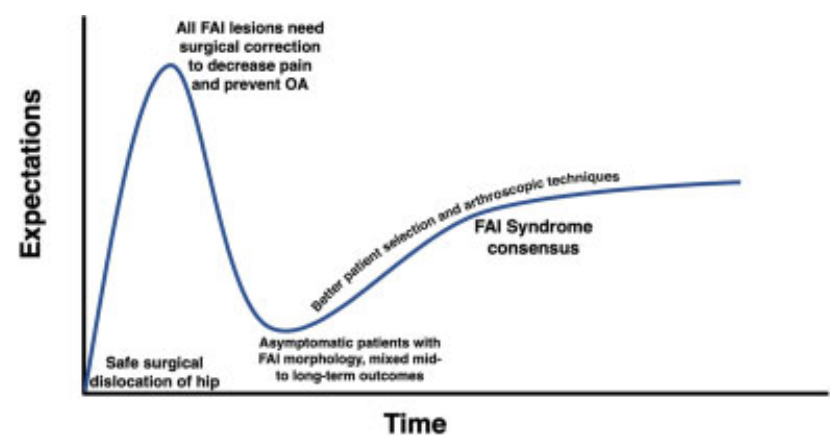

Fig. 4 The femoroacetabular impingement (FAI) hype cycle. The phases of the hype cycle as they relate to FAI syndrome. OA, osteoarthritis.

acetabulum and the (re)birth of the concept of FAI. Ganz and colleagues proposed this so-called new disease as a cause for hip OA and proposed treatments as a way of preventing or delaying the onset of hip OA. ${ }^{1}$ Specifically, they championed the use of osteochondroplasty of the femoral head-neck junction as a treatment for asphericity of the femoral head and periacetabular osteotomy as a treatment for acetabular version abnormalities. In essence, this was a "new" disease with a new treatment.

2. Everyone has FAI and treating it will delay/prevent hip $O A$ (Peak of inflated expectations): The publication and popularization of the concept of FAI and the interest and adaptation of the surgical techniques proposed by Ganz et al heightened awareness of the concept of FAI. Also, the potential to prevent or delay hip OA was embraced enthusiastically worldwide. This resulted in a widespread boom in both the diagnosis and treatment of FAI. With the description of the magnetic resonance (MR) arthrographic findings in patients with cam-type FAI, ${ }^{10} \mathrm{MR}$ arthrography of the hip became the imaging modality of choice in assessing the extent of intra-articular damage in patients with FAI, in addition to better assessing the shape of the osseous deformities. Advances in hip arthroscopy also increased access to surgeons who could treat the anatomical "abnormalities" in and around the hip joint. ${ }^{11}$ There was a significant trend toward early surgery for patients with hip pain with the goal of decreasing pain, improving range of motion, and preventing/delaying OA. The enthusiasm, particularly in the surgical community, led to certain centers performing prophylactic surgery on asymptomatic hips that demonstrated the morphological findings described by the Bern group. The idea was to operate and correct/modify the underlying osseous anatomy and thus prevent future damage to the cartilage and labrum (unpublished data). Expectations skyrocketed as did the volume of hip imaging and hip surgeries for FAI.

3. Does FAI even exist? How should we treat it? (Trough of disillusionment): The heightened awareness of the 
concept of FAI and the recognition of the osseous findings on imaging led to the realization that these osseous morphologies were quite prevalent in the general population. In fact, the more one looked, the more one saw the bump or the acetabular retroversion on imaging studies done for purposes that were completely unrelated to hip pain. ${ }^{12-16}$ If so many people had these osseous morphologies but were asymptomatic, did FAI even exist?

This could be applied to the ever-common labral tears as well. The prevalence of labral tears in the asymptomatic population was also found to be quite high. ${ }^{17}$ Are labral tears a cause for pain? Is their presence even relevant in the setting of FAI and hip pain?

In addition, postoperative midterm data began to emerge for both open and arthroscopic treatments for FAI. Although short-term data had been very encouraging, midterm data showed significant heterogeneity in outcomes for FAI surgery. Also, there was significant inconsistency in the manner of reporting outcomes. ${ }^{18-20}$ It was thus unclear who truly benefited most from surgery or whether surgery was the best first-line treatment for FAI. All of these uncertainties regarding the diagnosis and treatment of FAI led to significant disillusionment and skepticism in the medical community and, to a lesser degree, the athletic community.

4. FAI exists but ... (Slope of enlightenment): The uncertainties and skepticism were recognized, and great efforts were made to better understand the pathophysiology of FAI. One of the clear shortcomings was the lack of consensus on the precise definition and terminology that should be used. What is an abnormal head-neck junction? What thresholds should be used for $\alpha$ angles, lateral center-edge angles, acetabular version, femoral torsion, and so on? How much is too much or too little? Are these abnormalities or just morphological variants?

Along those lines, consensus was needed to move forward with more consistent and homogeneous research. This would help in determining the best means for diagnosing and treating FAI. The Warwick agreement was an important step in better defining the entity and proposed calling it femoroacetabular impingement syndrome (FAIS). ${ }^{21}$ In addition, definitions were refined including specifying that FAIS is a combination of symptoms, signs, and imaging findings. All three must be present. Also, regarding the terminology, it was recognized that cam and pincer so-called deformities were very common in the asymptomatic population and, for that reason, would best be described as morphologies as opposed to deformities or abnormalities.

On the diagnostic front, research into best imaging strategies has gained traction. To date, most imaging research has focused on selecting the best radiographic views to assess osseous morphologies or assessing whether conventional non-arthrographic hip MRI can adequately replace the current preferred hip MR arthrography in assessing the status of the labrum and cartilage. ${ }^{22-24}$
Also, recent studies assessed regional variations in hip cartilage properties that may mimic cartilage damage. ${ }^{25}$ In terms of treatment, there was increasing recognition of the role of nonoperative management of patients with FAIS. Recently, the results of the first randomized controlled trial of arthroscopy versus best conservative therapy was published. ${ }^{26}$ Other such trials are underway including ones comparing operative with nonoperative management as well as comparing osteochondroplasty with or without labral repair to lavage. ${ }^{27,28}$

All these active fronts in research are a clear indication of a desire to better understand FAIS including its pathophysiology, clinical presentation, imaging appearance, and optimal treatment for different subgroups of patients. These are clear indicators of the slope of enlightenment.

5. How to address FAI syndrome (Plateau of productivity): This is where we are today, close to the inflection point between the slope of enlightenment and the plateau of productivity. With a better understanding of the pathology and the prevalence of imaging findings in the asymptomatic population, a more precise definition of FAIS (triad of symptoms, signs, and imaging), and the recognition that not all patients require surgery, the medical community can now make more informed decisions regarding how to approach patients with FAIS. This should lead to a more homogeneous and consistent way to manage patients with FAIS. Achieving that level of homogeneity will be beneficial for the medical community, will allow the scientific community to perform better midand long-term studies regarding the syndrome, and hopefully lead to better patient care.

In conclusion, hip impingement and FAIS have followed Amara's law with initial overestimation and subsequent underestimation of the effects of FAI surgery, and they have followed the roller-coaster pattern of the hype cycle. There was an initial introduction of a new technique of safely dislocating a hip, a peak of inflated expectation of surgical treatment of FAIS, followed by a trough of disillusionment after the recognition of the large prevalence of imaging findings in an asymptomatic population as well as mixed results and uncertainty. This was followed by the slope of enlightenment as FAIS was better defined by an international consensus and thus has allowed much progress on understanding the syndrome and the variety of treatment strategies. Hopefully, we are near the inflection point where, with this better understanding and more high-quality research, there will be more precise and effective treatment strategies for patients with FAIS.

And beware... artificial intelligence (AI) is really starting to take off in clinical medicine and particularly in radiology. Are we ready for a roller-coaster ride on the AI hype cycle?

Conflict of Interest

None declared. 


\section{References}

1 Ganz R, Parvizi J, Beck M, Leunig M, Nötzli H, Siebenrock KA. Femoroacetabular impingement: a cause for osteoarthritis of the hip. Clin Orthop Relat Res 2003;(417):112-120

2 Ganz R, Gill TJ, Gautier E, Ganz K, Krügel N, Berlemann U. Surgical dislocation of the adult hip a technique with full access to the femoral head and acetabulum without the risk of avascular necrosis. J Bone Joint Surg Br 2001;83(08):1119-1124

3 Gautier E, Ganz K, Krügel N, Gill T, Ganz R. Anatomy of the medial femoral circumflex artery and its surgical implications. J Bone Joint Surg Br 2000;82(05):679-683

4 Truntzer JN, Shapiro LM, Hoppe DJ, Abrams GD, Safran MR. Hip arthroscopy in the United States: an update following coding changes in 2011. J Hip Preserv Surg 2017;4(03):250-257

5 Oxford Reference. Roy Amara 1925-2007, American futurologist. Available at: http://www.oxfordreference.com/view/10.1093/ acref/9780191826719.001.0001/q-oro-ed4-00018679. Accessed November 2018

6 Collins JA, Ward JP, Youm T. Is prophylactic surgery for femoroacetabular impingement indicated? A systematic review. Am J Sports Med 2014;42(12):3009-3015

7 Palmer AJ, Malak TT, Broomfield J, et al. Past and projected temporal trends in arthroscopic hip surgery in England between 2002 and 2013. BMJ Open Sport Exerc Med 2016;2(01):e000082

8 Medline (PubMed) trend. Keywords: Hip arthroscopy and hip impingement. Alexandru Dan Corlan. Medline trend: automated yearly statistics of results for any query, 2004. Web resource at URL http:// dan.corlan.net/medline-trend.html. Accessed November 2018

9 Gartner Hype Cycle. Interpreting technology hype. Available at: https://www.gartner.com/en/research/methodologies/gartner-hype-cycle. Accessed November 2018

10 Kassarjian A, Yoon LS, Belzile E, Connolly SA, Millis MB, Palmer WE. Triad of MR arthrographic findings in patients with cam-type femoroacetabular impingement. Radiology 2005;236(02):588-592

11 Kelly BT, Williams RJ III, Philippon MJ. Hip arthroscopy: current indications, treatment options, and management issues. Am J Sports Med 2003;31(06):1020-1037

12 Hack K, Di Primio G, Rakhra K, Beaulé PE. Prevalence of cam-type femoroacetabular impingement morphology in asymptomatic volunteers. J Bone Joint Surg Am 2010;92(14):2436-2444

13 Reichenbach S, Jüni P, Werlen S, et al. Prevalence of cam-type deformity on hip magnetic resonance imaging in young males: a cross-sectional study. Arthritis Care Res (Hoboken) 2010;62(09): 1319-1327

14 Frank JM, Harris JD, Erickson BJ, et al. Prevalence of femoroacetabular impingement imaging findings in asymptomatic volunteers: a systematic review. Arthroscopy 2015;31(06):1199-1204

15 Thier S, Gerisch D, Weiss C, Fickert S, Brunner A. Prevalence of cam and pincer deformities in the X-rays of asymptomatic individuals. BioMed Res Int 2017;2017:8562329

16 Mascarenhas VV, Rego P, Dantas P, et al. Imaging prevalence of femoroacetabular impingement in symptomatic patients, athletes, and asymptomatic individuals: a systematic review. Eur J Radiol 2016;85(01):73-95
17 Tresch F, Dietrich TJ, Pfirrmann CWA, Sutter R. Hip MRI: prevalence of articular cartilage defects and labral tears in asymptomatic volunteers. A comparison with a matched population of patients with femoroacetabular impingement. J Magn Reson Imaging 2017;46(02):440-451

18 Reiman MP, Peters S, Sylvain J, Hagymasi S, Ayeni OR. Prevalence and consistency in surgical outcome reporting for femoroacetabular impingement syndrome: a scoping review. Arthroscopy 2018;34(04):1319-1328.e9

19 Pierannunzii L, Di Benedetto P, Carulli C, et al. Mid-term outcome after arthroscopic treatment of femoroacetabular impingement: development of a predictive score. Hip Int 2018; July 1 (Epub ahead of print)

20 Perets I, Chaharbakhshi EO, Shapira J, Ashberg L, Mu BH, Domb BG. Hip arthroscopy for femoroacetabular impingement and labral tears in patients younger than 50 years: minimum five-year outcomes, survivorship, and risk factors for reoperations. J Am Acad Orthop Surg 2018

21 Griffin DR, Dickenson EJ, O’Donnell J, et al. The Warwick Agreement on femoroacetabular impingement syndrome (FAI syndrome): an international consensus statement. Br J Sports Med 2016;50(19):1169-1176

22 Atkins PR, Shin Y, Agrawal P, et al. Which two-dimensional radiographic measurements of cam femoroacetabular impingement best describe the three-dimensional shape of the proximal femur? Clin Orthop Relat Res 2019;477(01):242-253

23 Sutter R, Zubler V, Hoffmann A, et al. Hip MRI: how useful is intraarticular contrast material for evaluating surgically proven lesions of the labrum and articular cartilage? AJR Am J Roentgenol 2014;202(01):160-169

24 Linda DD, Naraghi A, Murnaghan L, Whelan D, White LM. Accuracy of non-arthrographic 3T MR imaging in evaluation of intraarticular pathology of the hip in femoroacetabular impingement. Skeletal Radiol 2017;46(03):299-308

25 Watanabe A, Boesch C, Siebenrock K, Obata T, Anderson SE. T2 mapping of hip articular cartilage in healthy volunteers at 3T: a study of topographic variation. J Magn Reson Imaging 2007;26(01): 165-171

26 Griffin DR, Dickenson EJ, Wall PDH, et al; FASHIoN Study Group. Hip arthroscopy versus best conservative care for the treatment of femoroacetabular impingement syndrome (UK FASHIoN): a multicentre randomised controlled trial. Lancet 2018;391(10136): 2225-2235

27 Simunovic N, Heels-Ansdell D, Thabane L, Ayeni OR; FIRST Investigators. Femoroacetabular Impingement Randomised controlled Trial (FIRST): a multi-centre randomized controlled trial comparing arthroscopic lavage and arthroscopic osteochondroplasty on patient important outcomes and quality of life in the treatment of young adult (18-50 years) femoroacetabular impingement: a statistical analysis plan. Trials 2018;19(01):588

28 Palmer AJ, Ayyar-Gupta V, Dutton SJ, et al. Protocol for the Femoroacetabular Impingement Trial (FAIT): a multi-centre randomised controlled trial comparing surgical and non-surgical management of femoroacetabular impingement. Bone Joint Res 2014;3(11):321-327 